\title{
Cortical excitability measured with transcranial magnetic stimulation in children with epilepsy before and after antiepileptic drugs
}

Ann-Charlotte Andreasson, Gudmundur V Sigurdsson, Goran Pegenius, Magnus Thordstein and Tove Hallbook

The self-archived postprint version of this journal article is available at Linköping University Institutional Repository (DiVA):

http://urn.kb.se/resolve?urn=urn:nbn:se:liu:diva-164080

N.B.: When citing this work, cite the original publication.

Andreasson, A., Sigurdsson, G. V, Pegenius, G., Thordstein, M., Hallbook, T., (2020), Cortical excitability measured with transcranial magnetic stimulation in children with epilepsy before and after antiepileptic drugs, Developmental Medicine \& Child Neurology. https://doi.org/10.1111/dmcn.1449o

Original publication available at:

https://doi.org/10.1111/dmcn.14490

Copyright: Wiley (12 months)

http://eu.wiley.com/WileyCDA/ 
[Original article: 2 tables, 2 figures, 1 online table]

Cortical excitability measured with transcranial magnetic stimulation in children with epilepsy before and after antiseizure medication

ANN-CHARLOTTE ANDREASSON ${ }^{1}$

GUDMUNDUR V SIGURDSSON ${ }^{1}$

GÖRAN PEGENIUS ${ }^{2}$

MAGNUS THORDSTEIN ${ }^{3, *}$

TOVE HALLBÖÖK ${ }^{1, *}$

1 Department of Pediatrics, Institute of Clinical Sciences, The Queen Silvia Children's Hospital, University of Gothenburg, Gothenburg; 2 Department of Clinical Neurophysiology, Sahlgrenska University Hospital, University of Gothenburg, Gothenburg; 3 Department of Clinical Neurophysiology, Institute of Clinical and Experimental Medicine, Linköping University, Linköping, Sweden.

\section{*Joint senior authors.}

Correspondence to Tove Hallböök, Pediatric Neurology, Queen Silvia Children’s Hospital Sahlgrenska University, 41685 Gothenburg, Sweden. E-mail: tove.hallbook@vgregion.se

\section{PUBLICATION DATA}

Accepted for publication 00th Month 2019.

Published online 00th Month 2019. 
ABBREVIATIONS

ASM Antiseizure medication

CSP Cortical silent period

GABA $\quad \gamma$-aminobutyric acid

ICF Intracortical facilitation

LICI Long intracortical inhibition

MEP Motor-evoked potential

RMT Resting motor threshold

SICI Short intracortical inhibition

TMS Transcranial magnetic stimulation

[abstract]

AIM To evaluate cortical excitability with transcranial magnetic stimulation (TMS) in children with new-onset epilepsy before and after antiseizure medication (ASM).

METHOD Fifty-five drug-naïve patients (3-18y, 29 females, 26 males) with new-onset epilepsy were recruited from 1st May 2014 to 31st October 2017 at the Child Neurology Department, Queen Silvia's Children's Hospital, Gothenburg, Sweden. We performed TMS in 48 children with epilepsy ( 27 generalized and 21 focal) before and after the introduction of ASM. We used single- and paired-pulse TMS. We used single-pulse TMS to record resting motor thresholds (RMTs), stimulus-response curves, and cortical silent periods (CSPs). We used paired-pulse TMS to record intracortical inhibition and facilitation at short, long, and intermediate intervals.

RESULTS There were no differences in cortical excitability between children with generalized and focal epilepsy at baseline. After ASM treatment, RMTs increased ( $p=0.001)$, especially in children receiving sodium valproate $(p=0.005)$. CSPs decreased after sodium valproate was 
administered $(p=0.05)$. As in previous studies, we noted a negative correlation between RMT and age in our study cohort. Paired-pulse TMS could not be performed in most children because high RMTs made suprathreshold stimulation impossible.

INTERPRETATION Cortical excitability as measured with RMT decreased after the introduction of ASM. This was seen in children with both generalized and focal epilepsy who were treated with sodium valproate, although it was most prominent in children with generalized epilepsy. We suggest that TMS might be used as a prognostic tool to predict ASM efficacy.

[First page footer]

(C) Mac Keith Press 2019

DOI: $10.1111 / \mathrm{dmcn} \cdot \mathrm{xxxxx}$

[Left page footer]

Developmental Medicine \& Child Neurology 2019, 60: 000-000

[Right page footer]

Cortical Excitability in Children with Epilepsy Tove Hallböök et al.

\section{What this paper adds}

- Resting motor threshold (RMT) correlated negatively with age in children with epilepsy.

- No differences in cortical excitability were noted between patients with generalized and focal epilepsy.

- Treatment with antiseizure medication decreased cortical excitability as measured with transcranial magnetic stimulation (TMS).

- Decreased cortical excitability with increased RMT was recorded, especially after sodium valproate treatment. 
- Paired-pulse TMS was difficult to perform because of high RMTs in children.

[main text]

Epilepsy is characterized by an imbalance between excitatory and inhibitory mechanisms that may result in increased cortical excitability and recurrent epileptic seizures. Epilepsy is classified as focal, generalized, combined focal and generalized, and unknown. ${ }^{1}$ Most children with epilepsy will be seizure-free when antiseizure medication (ASM) is administered. ${ }^{2}$ The main mechanisms of action of ASM are modulation of voltage-gated ion channels, enhancement of synaptic inhibition, and inhibition of synaptic excitation. ${ }^{3}$

Transcranial magnetic stimulation (TMS) was first described in 1985 by Barker et al. ${ }^{4}$ as a non-invasive technique that could be used to directly stimulate the human motor cortex. TMS is based on the fundamental principles of electromagnetic induction. A pulse of electric current in the stimulation coil produces a magnetic field that is oriented perpendicular to the plane of the coil. When the coil is placed over the head of the patient, the time-varying magnetic field induces electrical currents in the brain. When this is done over the cortical motor areas, the current depolarizes neurons, initiating action potentials from the cortex along the spinal cord to the peripheral nerves, which results in muscle contraction mainly contralateral to the stimulation site. Muscle activation produces motor-evoked potentials (MEPs) that can be measured with electromyography. ${ }^{4}$

Specific inhibitory and excitatory functions can be evaluated with TMS protocols that use either single- or paired-pulse TMS. ${ }^{5,6}$ Resting motor thresholds (RMTs), stimulus-response curves, and cortical silent periods (CSPs) are evaluated with single-pulse TMS. Short intracortical inhibition (SICI), intracortical facilitation (ICF), and long intracortical inhibition (LICI) are assessed with paired-pulse TMS. RMTs reflect axonal excitability primarily mediated by ion channels $;^{7,8}$ stimulus-response curves reflect excitability through the number of cortical motor neurons activated and recruited in the spinal cord. ${ }^{8} \mathrm{CSP}$ duration in a slightly 
contracted muscle reflects the activity of $\gamma$-aminobutyric acid (GABA) $)_{A}$ and $\mathrm{GABA}_{\mathrm{B}}$ receptormediated inhibitory neurotransmission. ${ }^{9}$ During paired-pulse TMS, two consecutive pulses are applied: a subthreshold conditioning pulse and a suprathreshold stimulus pulse, with a variable interstimulus interval resulting in inhibition or facilitation depending on the intensity and duration of the interval. SICI $(1-5 \mathrm{~ms})$ is thought to be related to $\mathrm{GABA}_{\mathrm{A}}$ receptor-mediated inhibition; LICI $(50-400 \mathrm{~ms})$ is thought to be related to $\mathrm{GABA}_{\mathrm{B}}$ receptor-mediated inhibition. ${ }^{5,10}$ ICF $(6-30 \mathrm{~ms})$ is related to $N$-methyl-D-aspartic acid receptor-mediated facilitation, while $\mathrm{GABA}_{\mathrm{A}}$ is related to mediated inhibition. ${ }^{5,11}$

Although hyperexcitability has been reported in adult patients with epilepsy, results have not been consistent and have been difficult to compare due to differences in patient populations and methodologies that use different excitability variables. ${ }^{12,13}$ In a recent review, de Goede et al. ${ }^{14}$ identified 31 articles where cortical excitability had been estimated using both single- and paired-pulse TMS in typically developing controls and drug-naïve patients with epilepsy. Cortical excitability was increased in most patients, especially in those with generalized epilepsy. In a meta-analysis, Brigo et al. ${ }^{15}$ reported significant decreases in RMTs in patients with drug-naïve juvenile myoclonic epilepsy and a trend towards lower RMTs in patients with generalized epilepsy compared to typically developing controls. Decreased cortical excitability after the introduction of ASM in patients with epilepsy has been described in several studies. ${ }^{3,16,17}$ Ziemann et al. ${ }^{11}$ described that voltage-dependent sodium and calcium channel blockers elevate RMTs, whereas GABAergic ASMs increase intracortical inhibition and reduce $\mathrm{ICF}^{3}$ In epilepsy treated successfully, hyperexcitability normalized over time in seizure-free patients, but remained increased in those who continued to have seizures despite ASM treatment. ${ }^{17,18}$ Children have higher RMTs than adults and RMTs decrease and reach adult levels by middle adolescence. ${ }^{19,20}$ Some adult studies have included adolescents from the age of 14 years onwards. To our knowledge, there is only one study describing cortical excitability 
in children with epilepsy younger than 14 years of age. ${ }^{21}$ In that study, 13 patients (9-14y) with benign electroclinical syndrome with centrotemporal spikes and 10 age-matched controls were described. Although no motor cortical hyperexcitability was recorded in untreated patients or typically developing controls, a decrease in excitability with increased RMTs was seen in eight patients treated with sodium valproate.

The aim of the present study was to describe cortical excitability using TMS in drug-naïve children with new-onset epilepsy before and after ASM treatment.

\section{METHOD}

\section{Patients}

Fifty-five drug-naïve patients (3-18y, 29 females, 26 males) with new-onset epilepsy were recruited from 1st May 2014 to 31st October 2017, at the Child Neurology Department, Queen Silvia's Children's Hospital, Gothenburg, Sweden. The diagnoses were based on the International League Against Epilepsy classification of epilepsy. ${ }^{1}$ Seven patients (six females) were excluded: we could not define motor thresholds in three females since they were above the equipment's maximum output; one patient had psychogenic non-epileptic seizures; two patients never started ASM treatment; and one patient withdrew consent. The remaining 48 patients ( 23 females) were assessed with TMS before and 3 months after the introduction of ASM. Electroencephalography (EEG) was performed before ASM in all patients and in 38 patients after 3 months. The second EEG could not be performed in 10 patients due to practical reasons. EEG pathology was deemed generalized if generalized spike and wave activity was recorded and focal if the EEG only showed focal epileptiform discharges. Epilepsy was categorized as generalized or focal according to seizure type and EEG pathology. ${ }^{1}$ ASM treatment was initiated according to international guidelines. ${ }^{2}$ Magnetic resonance imaging 
(MRI) of the brain was not required for diagnosis and was not performed in the patients at this early stage of the disease.

\section{'Pseudo-navigation' TMS}

All TMS sessions were conducted between 9 a.m. and 3 p.m. Pseudo-navigated TMS refers to the use of DEMO MRI data from the system being used (eXimia NBS; Nexstim Ltd., Helsinki, Finland), which is freely available. Navigated stimulation was performed based on these data. Since information on stimulation parameters can be saved in the system, the same location was stimulated on both occasions. Stimulation was performed with a figure-of-eight shaped coil using biphasic pulses and posterior-anterior direction of the main induced current as described previously. ${ }^{22,23}$ Stimuli were delivered over the primary motor area in the dominant hemisphere (depending on handedness). A surface electromyography (EMG) recording was made from the abductor pollicis brevis muscle and its main location of activation was sought out. During stimulation, patients were awake with their eyes open but were physically inactive. Single- and paired-pulse TMS was used to evaluate cortical excitability as detailed in the next sections.

\section{TMS parameters}

\section{Single-pulse TMS}

\section{$R M T$}

The RMT of the abductor pollicis brevis muscle was estimated both as a percentage (percentage RMT) of stimulator output and as electrical field strength (RMT V/m). The latter can be obtained online by using the eXimia NBS system and was used to calculate all intensities during testing. We used single pulses after establishing the optimal point of stimulation of the primary motor cortex at muscle rest (verified by continuous visual observation of the EMG). RMT was defined as the lowest stimulation intensity that produced an MEP in the target muscle with a peak-to-peak amplitude greater than $20 \mu \mathrm{V}$ in 5 or more trials out of 10 trials. $^{24}$ 
CSP

CSP refers to a period of extremely low EMG amplitude after a MEP in a voluntarily contracted target muscle. Single-pulse stimulation $(150 \%$ of individually defined RMTs or $100 \%$ stimulator output in those with high thresholds) was used. CSP duration in milliseconds (ms) was determined visually by the offline position of two cursors: at the start of the MEP and at the first reappearance of EMG activity respectively.

Stimulus-response curve

The amplitude $(\mu \mathrm{V})$ of the MEP increases with stimulation intensity. Stimulus-response curves were assessed by gradually increasing stimulation from $100 \%$ to $110 \%, 120 \%, 130 \%, 140 \%$ and $150 \%$ of the individually defined RMTs. Each stimulus-response curve was based on six MEP amplitudes from increasingly intense stimuli. A linear regression was used to find the line of best fit; the slope ( $\mu \mathrm{V} / \Delta$ percentage RMT) of the line's equation was compared between the first and second measurement using a paired-sample $t$-test.

\section{Paired-pulse TMS}

Paired-pulse stimulation at various interstimulus intervals was applied over the optimal point of stimulation of the motor cortex to assess the three parameters of cortical excitability described earlier: ICF, SICI, and LICI. These were assessed using $10 \mathrm{~ms}, 2 \mathrm{~ms}$, and $80 \mathrm{~ms}$ intervals with RMT conditioning pulses of $95 \%, 70 \%$, and $110 \%$ for ICF, SICI, and LICI respectively. The second pulse was given at $110 \%$ RMT for all three paradigms.

\section{Statistical analysis}

Statistical analyses were performed with SPSS v24 (IBM Corp., Armonk, NY, USA). Continuous variables are presented as the mean $\pm \mathrm{SD}$ if normally distributed, otherwise as the median (range). To identify the type of epilepsy (generalized vs focal) on percentage RMT, RMT V/m, and CSP at baseline, we used a multiple linear regression with percentage RMT, RMT V/m, and CSP as the dependent variables and epilepsy type and age as the covariates. 
Linear regression analysis was also used to calculate the line of best fit for all six stimulusresponse curve measurements; the slope of the lines was used as a variable to compare baseline and follow-up. Changes in parameters (percentage RMT, RMT V/m, CSP, and stimulusresponse curve slopes) between baseline and follow-up were evaluated using paired-sample $t$ tests for parametric variables; Wilcoxon signed-rank tests were used for non-parametric variables. The correlation between age and percentage RMT was estimated with the Spearman's rank correlation coefficient $(r)$. All tests were two-tailed; a significance level of 0.05 was deemed statistically significant.

\section{Ethical approval}

The study was approved by the University of Gothenburg regional board of medical ethics (diary number 548-13). Written informed consent was obtained from all parents and from participants older than 15 years.

\section{RESULTS}

The clinical data at baseline are shown in Table 1. Comorbidities were identified in seven patients: one had cerebral palsy; two had attention-deficit/hyperactivity disorder; three had a speech disorder; one had autism spectrum disorder combined with attentiondeficit/hyperactivity disorder and a speech disorder. Five patients had a history of febrile seizures. In the 38 patients who underwent a second EEG, 20 had generalized epilepsy. In 10 of these patients, EEG was normalized; in 10 patients, EEG pathology was unchanged. Eighteen patients had focal epilepsy; all had unaltered EEG pathology.

\section{TMS parameters}

\section{Single-pulse TMS}


An age-dependent correlation of RMT and age, with higher motor thresholds in younger patients, was observed (Fig. 1). At baseline, no significant differences between RMT and CSP were noted between patients with generalized and focal epilepsy (data not shown).

There was a significant decrease in cortical excitability (defined as percentage RMT) between baseline and follow-up (Table S1, online supporting information) in both patients with generalized and focal epilepsy ( $p=0.04$ and $p=0.03$ respectively). RMT assessed as RMT V/m did not change significantly. CSP duration at follow-up was shorter in all patients, with a trend towards statistical significance in those with generalized epilepsy $(p=0.05)$.

In patients with generalized epilepsy who received sodium valproate (11 out of 27), both RMT parameters increased significantly between baseline and follow-up $(p=0.005)$. No significant changes were noted in patients who received ethosuximide ( 2 out 27 ), lamotrigine (3 out 27), and levetiracetam (11 out of 27). CSP duration tended to decrease after treatment with sodium valproate $(p=0.07)$. In patients with focal epilepsy, there was a significant increase in percentage $\mathrm{RMT}(p=0.04)$ after sodium valproate was started (6 out of 21$)$; no such increase was noted with lamotrigine ( 3 out of 21 ) or oxcarbazepine (12 out of 21$)(p=0.2$ and $p=0.4$ respectively). Cortical excitability (assessed as RMT V/m and CSP) was not significantly changed after treatment. Thirty-four patients (17 in each of the two groups) were seizure-free at follow-up. The increase in percentage RMT was more prominent in seizure-free patients and patients with fewer seizures compared to those with more seizures (Fig. 2). It was most prominent in the 10 patients with generalized epilepsy who were seizure-free and had a normalized EEG (percentage RMT at baseline $47.0 \pm 14.6$ vs $54.3 \pm 20.1$ at follow-up, $p=0.042$ ) and especially in the six patients treated with sodium valproate (percentage RMT at baseline $47.3 \pm 17.9$ vs $59.8 \pm 23.6$ at follow-up, $p=0.022 ;$ RMT V/m at baseline $87.2 \pm 38.5$ vs $117.5 \pm 42.1$ at follow-up, $p=0.003)$.

\section{Stimulus-response curves}


Stimulus-response curves at both time points were obtained in 31 out of 48 patients. In 17 patients, this was not possible due to high motor thresholds. Significantly decreased slopes $(\mu \mathrm{V} / \Delta$ percentage $\mathrm{RMT}$ ) at follow-up were seen for the 31 patients (mean difference $11.5,95 \%$ confidence interval $[\mathrm{CI}]=2.8-20.3, p=0.01)$ and in the group of 19 patients with generalized epilepsy (mean difference 15.3, 95\% CI=3.9-26.8, $p=0.01$ ). When we investigated the effects of the different ASMs, a significant decrease was seen only in seven patients with generalized epilepsy treated with sodium valproate (mean difference $15.1,95 \% \mathrm{CI}=1.1-29.2, p=0.039$ ).

\section{Paired-pulse TMS}

Because of the definition of the paired-pulse paradigms (SICI, LICI, ICF) and because RMT in this age group is high, the paired-pulse TMS assessments at baseline and follow-up could only be made in a minority of patients. SICI was recorded in eight, LICI in seven, and ICF in 17 of the 48 patients. Because of the small sample size, further analyses were not indicated.

\section{DISCUSSION}

To our knowledge, this study is the first attempt to describe cortical excitability using TMS in children with new-onset, drug-naïve epilepsy before and after the administration of ASM. In this longitudinal follow-up study, we performed excitability tests using TMS before and after ASM was started. Our aim was to achieve optimal conditions for the TMS sessions by carefully preparing participants. Examinations were performed by one experienced biomedical assistant, using identical equipment and individually defined stimulation parameters, recorded at the same time of day. Motor thresholds correlated negatively with age. This has been described in typically developing children ${ }^{19}$ and we can confirm this in children with epilepsy.

At baseline, no significant differences were noted regarding the single-pulse TMS paradigms between patients with generalized and focal epilepsy. In line with earlier studies in adult patients, we found a significant change in these paradigms after the initiation of ASM.,36,17 
This was seen in both patients with generalized and focal epilepsy and specifically when sodium valproate was administered. This is in agreement with a previous study of children with Rolandic epilepsy treated with sodium valproate. ${ }^{21}$ ASMs that block voltage-gated sodium channels, in particular carbamazepine, lamotrigine, and oxcarbazepine have been shown to increase motor thresholds. ${ }^{3}$ We could not confirm this in our study because a relatively small number of patients received these types of ASM. The number of patients receiving sodium valproate was higher in our study and, as also reported by Nezu et al., ${ }^{21}$ a significant decrease in excitability (increased RMT) was seen in these patients. This decreased excitability detected early on and measured with TMS might be a useful prognostic tool to predict ASM efficacy. With regard to the stimulus-response curves, they indicated reduced excitability after the ASM was introduced. Stimulus-response curves reflect the sum effect of activities in the corticospinal system. ${ }^{8}$ In the relaxed hand muscles of population norm adults, RMT is about $20 \%$ stimulator output and the curve is satisfied at about $70 \%$ stimulator output. $^{8}$ As expected, the corresponding values in the present group of children were substantially higher; such high levels precluded the performance of the test in $35 \%$ of patients. ASM induced decreased excitatory/increased inhibitory level of the corticospinal system, shown by the reduced slope of the curves, and may be explained by the effects on all levels of the chain of neural elements involved, from activation of cortical components to that of the recorded muscle. ${ }^{8}$ Since all experimental conditions apart from the ASM were kept constant, we believe our findings represent a true change in excitability induced by medication.

We found a paradoxical reduction in CSP duration after ASM initiation. This may be explained by hyperactivation of inhibitory circuits in patients with epilepsy acting as a protective mechanism to prevent seizure recurrence. ${ }^{14,25}$ After treatment with ASM, these compensatory mechanisms may be less active. These initial compensatory mechanisms may 
not be present in patients with chronic epilepsy ${ }^{26,27}$ as opposed to the patients in our study who were drug-naïve and presented with new-onset epilepsy.

In earlier studies in adult patients, the paired-pulse TMS parameters SICI and LICI indicated more consistent results of increased excitability in patients with both focal and generalized epilepsy compared to single-pulse TMS parameters. ${ }^{14}$ In our study, we had difficulties in obtaining data for paired-pulse TMS because high RMTs prevented us from performing suprathreshold stimulation. Thus, it seems that paired-pulse TMS paradigms in their standard form have a low yield when used in children. Since RMTs were near the maximum of machine output, suprathreshold stimulation could not or could only partly be carried out. We could have tried to overcome this by using the active muscle motor threshold since this can be elicited at lower stimulation intensities. However, assessing the active muscle motor threshold requires the child to be able to activate a specific muscle to a certain degree for some time. Results may also be uncertain since MEPs are more difficult to distinguish from background muscle activity in the EMG of an activated muscle. These considerations made us opt for RMT instead of the active muscle motor threshold. In patients with generalized epilepsy, no interhemispheric differences in cortical excitability have been observed; therefore, either side can be examined. ${ }^{26,28,29}$ In contrast, in patients with focal epilepsy, examination of cortical excitability should ideally be performed in both affected and non-affected hemispheres. ${ }^{26,28,29}$ Badawy et al. ${ }^{26}$ reported that in drug-naïve focal epilepsy, cortical excitability evaluated with paired-pulse TMS was increased in the hemisphere ipsilateral to the epileptic focus, but not in the contralateral hemisphere. ${ }^{26}$ In our study, we examined the dominant hemisphere. One might argue that the use of standard MRI for TMS navigation was suboptimal. However, the optimal level of stimulation was defined from functional assessment and the navigation system we used ensured that the same location was stimulated at both times of testing. 
The strengths of the study are the longitudinal setting with assessment before and after the initiation of ASM and patients representing a homogenous group, namely presenting with newonset epilepsy and being drug-naïve. Weaknesses include a small sample size and patients being of different ages. This suggests that the magnitude of findings reported in this study may be underestimated.

In conclusion, excitability (as assessed by RMT) was significantly decreased after ASM was administered in children with drug-naïve, new-onset epilepsy. This was seen in both generalized and focal epilepsy but was most prominent in patients with generalized epilepsy, especially patients treated with sodium valproate. Future studies will need larger cohorts. Additionally, individual thresholds recorded using active muscle motor threshold and MRI for navigated TMS may improve outcomes.

\section{ACKNOWLEDGEMENTS}

This work was supported by the Margarethahemmets, Torbjörn Jebners, Petter Silverskiölds, and Drottning Silvias Jubileums Foundations. We thank Paul Uvebrant for his valuable support and the participants of this study.

The authors have stated they had no interests that might be perceived as posing a conflict or bias.

\section{Supporting information}

The following additional material may be found online:

Table S1: Brain excitability measurements in children with epilepsy before and after treatment with antiseizure medication

\section{REFERENCES}


1. Scheffer IE, Berkovic S, Capovilla G, et al. ILAE classification of the epilepsies: position paper of the ILAE Commission for Classification and Terminology. Epilepsia 2017; 58: $512-21$

2. Glauser T, Ben-Menachem E, Bourgeois B, et al. Updated ILAE evidence review of antiepileptic drug efficacy and effectiveness as initial monotherapy for epileptic seizures and syndromes. Epilepsia 2013; 54: 551-63.

3. Ziemann U, Reis J, Schwenkreis P, et al. TMS and drugs revisited 2014. Clin Neurophysiol 2015; 126: 1847-68.

4. Barker AT, Jalinous R, Freeston IL. Non-invasive magnetic stimulation of human motor cortex. Lancet 1985; 325: 1106-7.

5. Kujirai T, Caramia MD, Rothwell JC, et al. Corticocortical inhibition in human motor cortex. J Physiol 1993; 471: 501-19.

6. Valls-Solé J, Pascual-Leone A, Wassermann EM, Hallet M. Human motor evoked responses to paired transcranial magnetic stimuli. Electroencephalogr Clin Neurophysiol 1992; 85: 355-64.

7. Rossini PM, Burke D, Chen R, et al. Non-invasive electrical and magnetic stimulation of the brain, spinal cord, roots and peripheral nerves: basic principles and procedures for routine clinical and research application. An updated report from an I.F.C.N Committee. Clin Neurophysiol 2015; 126: 1071-1107.

8. Devanne H, Lavoie BA, Capady C. Input-output properties and gain changes in the human corticospinal pathway. Exp Brain Res 1997; 114: 329-38.

9. Inghilleri M, Berardelli A, Cruccu G, Manfredi M. Silent period evoked by transcranial stimulation of the human cortex and cervicomedullary junction. $J$ Physiol 1993; 466: 52134. 
10. McDonnell MN, Orekhov $Y$, Ziemann $U$. The role of GABAB receptors in intracortical inhibition in the human motor cortex. Exp Brain Res 2006; 173: 86-93.

11. Ziemann U, Lönnecker S, Steinhoff BJ, Paulus W. Effects of antiepileptic drugs on motor cortex excitability in humans: a transcranial magnetic stimulation study. Ann Neurol 1996; 40: $367-78$.

12. Badawy RAB, Strigaro G, Cantello R. TMS cortical excitability and epilepsy: the clinical impact. Epilepsy Res 2014; 108: 153-61.

13. Tassinari CA, Cincotta M, Zaccara G, Michelucci R. Transcranial magnetic stimulation and epilepsy. Clin Neurophysiol 2003; 114: 777-98.

14. de Goede AA, Ter Braack EM, van Putten MJAM. Single and paired pulse transcranial magnetic stimulation in drug naïve epilepsy. Clin Neurophysiol 2016; 127: 3140-55.

15. Brigo F, Storti M, Benedetti MD, et al. Resting motor threshold in idiopathic generalized epilepsies: a systematic review with meta-analysis. Epilepsy Res 2012; 101: 3-13.

16. Reutens DC, Berkovic SF, Macdonell RA, Bladin PF. Magnetic stimulation of the brain in generalized epilepsy: reversal of cortical hyperexcitability by anticonvulsants. Ann Neurol 1993; 34: 351-5.

17. Badawy RA, Macdonell RA, Berkovic SF, Newton MR, Jackson GD. Predicting seizure control: cortical excitability and antiepileptic medication. Ann Neurol 2010; 67: 64-73.

18. Badawy RA, Jackson GD, Bercovic SF, Macdonell RA. Cortical excitability and refractory epilepsy: a three-year longitudinal transcranial magnetic stimulation study. Int $J$ Neural Syst 2013; 23: 1250030.

19. Garvey MA, Mall V. Transcranial magnetic stimulation in children. Clin Neurophysiol 2008; 119: 973-84. 
20. Garvey MA, Ziemann U, Bartko JJ, Denckla MB, Barker CA, Wassermann EM. Cortical correlates of neuromotor development in healthy children. Clin Neurophysiol 2003; 114: $1662-70$.

21. Nezu A, Kimura S, Ohtsuki N, Tanaka M. Transcranial magnetic stimulation in benign childhood epilepsy with centro-temporal spikes. Brain Dev 1997; 19: 134-7.

22. Thordstein M, Saar K, Pegenius G, Elam M. Individual effects of varying stimulation intensity and response criteria on area activation for different muscles in humans. A study using navigated transcranial magnetic stimulation. Brain Stimul 2013; 6: 49-53.

23. Danner N, Julkunen P, Könönen M, Säisänen L, Nurkkula J, Karhu J. Navigated transcranial magnetic stimulation and computed electric field strength reduce stimulatordependent differences in the motor threshold. J Neurosci Methods 2008; 174: 116-22.

24. Awiszus F. TMS and threshold hunting. Suppl Clin Neurophysiol 2003; 56: 13-23.

25. Cincotta M, Giovannelli F, Borgheresi A,Tramacere L, Viggiano MP, Zaccara G. A metaanalysis of the cortical silent period in epilepsies. Brain Stimul 2015; 8: 693-701.

26. Badawy RA, Curatolo JM, Newton M, Bercovic SF, Macdonell RA. Changes in cortical excitability differentiate generalized and focal epilepsy. Ann Neurol 2007; 61: 324-31.

27. Badawy RA, Vogrin SJ, Lai A, Cook MJ. Does the region of epileptogenicity influence the pattern of change in cortical excitability? Clin Neurophysiol 2015; 126: 249-56.

28. Badawy RA, Vogrin SJ, Lai A, Cook MJ. Patterns of cortical hyperexcitability in adolescent/adult-onset generalized epilepsies. Epilepsia 2013; 54: 871-8.

29. Lee JH, Joo EY, Seo DW, Hong SB. Lateralizing cortical excitability in drug naïve patients with generalized or focal epilepsy. J Epilepsy Res 2015; 5: 75-83. 
Table 1: Patient characteristics

\begin{tabular}{|c|c|c|c|}
\hline & $\begin{array}{l}\text { Generalized epilepsy } \\
(n=27)\end{array}$ & $\begin{array}{l}\text { Focal epilepsy } \\
(n=21)\end{array}$ & Total $(n=48)$ \\
\hline Age, y:mo, median (range) & $11: 6(4: 0-15: 4)$ & $9: 3(4: 6-15: 1)$ & $10: 0(4: 0-15: 4)$ \\
\hline Female sex & $14(52)$ & $9(43)$ & $23(48)$ \\
\hline \multicolumn{4}{|l|}{ Aetiology } \\
\hline Genetic & $16(59)$ & 0 & $16(33)$ \\
\hline Structural & $1(4)$ & $3(14)$ & $4(8)$ \\
\hline Unknown & $10(37)$ & $18(86)$ & $28(58)$ \\
\hline Seizure frequency, median (range) & $2(0.5-1500)$ & $1(1-60)$ & $2(0.5-1500)$ \\
\hline Comorbidities & $5(19)$ & $3(14)$ & $8(17)$ \\
\hline \multicolumn{4}{|l|}{ EEG } \\
\hline Normal & $1(4)$ & $1(5)$ & $2(4)$ \\
\hline Focal & 0 & $17(81)$ & $17(35)$ \\
\hline Multifocal & $2(7)$ & $2(9)$ & $4(8)$ \\
\hline Generalized & $24(89)$ & $1(5)$ & $25(52)$ \\
\hline
\end{tabular}

Data are $n(\%)$ unless otherwise stated. EEG, electroencephalogram. 


\section{Figure legends}

Figure 1: Correlation of excitability (resting motor threshold [RMT] percentage) and age in patients with focal and generalized epilepsy. Spearman's correlation coefficients: $r=-0.783$, $p<0.001$ (all patients, $n=48$ ); $r=-0.806, p<0.001$ (focal epilepsy, $n=21$ ); $r=-0.720, p<0.001$ (generalized epilepsy, $n=27$ ).

Figure 2: Resting motor threshold (RMT) before and after treatment in all 48 patients and broken down according to the three seizure frequency groups: seizure-free; three or fewer seizures per month; more than three seizures per month at follow-up. The bars represent the $95 \%$ confidence intervals. 


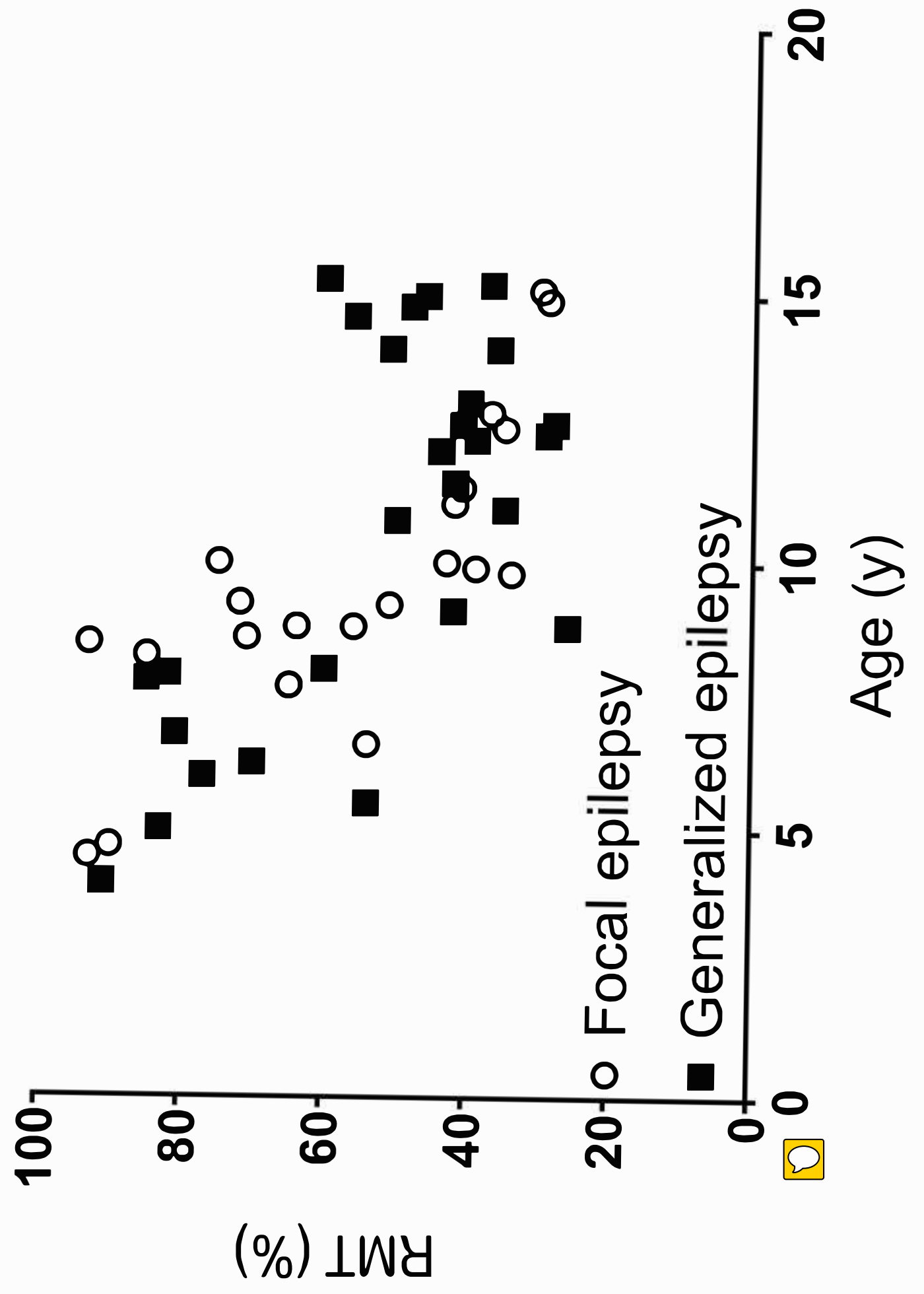




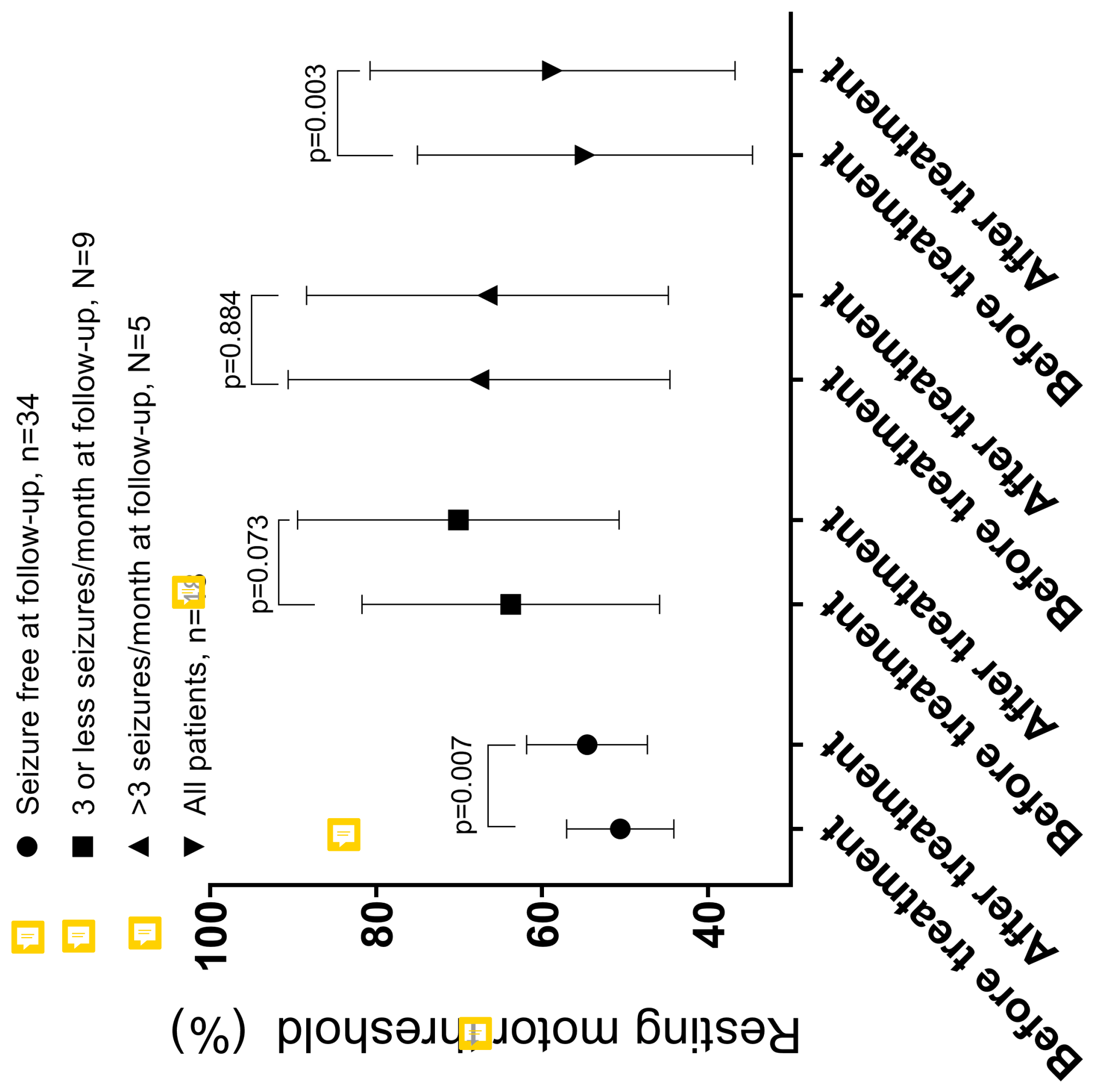


TABLE S1: Brain excitability measurements in children with epilepsy before and after treatment with antiseizure medication

\begin{tabular}{|c|c|c|c|c|c|c|c|c|c|c|c|c|}
\hline $\begin{array}{l}\text { EP type } \\
\text { and } \\
\text { treatment }\end{array}$ & $\begin{array}{l}\text { RMT } \\
\%-1\end{array}$ & $\begin{array}{l}\text { RMT \% } \\
-2\end{array}$ & $\begin{array}{l}\text { RMT \% } \\
-\Delta\end{array}$ & $\begin{array}{l}p- \\
\text { value }\end{array}$ & $\begin{array}{l}\text { RMT } \\
\text { V/m-1 }\end{array}$ & $\begin{array}{l}\text { RMT } \\
\mathrm{V} / \mathrm{m}-2\end{array}$ & $\begin{array}{l}\text { RMT } \\
\text { V/m- } \Delta\end{array}$ & $p$-value & CSP-1 & CSP-2 & CSP- $\Delta$ & $p$-value \\
\hline $\begin{array}{l}\text { All patients } \\
n 8\end{array}$ & $\begin{array}{l}50.5 \\
(26-93)\end{array}$ & $\begin{array}{l}54.5 \\
(30-100)\end{array}$ & $\begin{array}{l}2(-18- \\
28)\end{array}$ & 0.001 & \begin{tabular}{|l}
87.5 \\
$(57-270)$
\end{tabular} & $\begin{array}{l}99.5(54- \\
230)\end{array}$ & $\begin{array}{l}2.5(-87- \\
46)\end{array}$ & 0.296 & $\begin{array}{l}185.3 \\
\pm 42.7^{a}\end{array}$ & $\begin{array}{l}173.5 \\
\pm 33.7^{b}\end{array}$ & $\begin{array}{l}-10.9 \\
\pm 40.3\end{array}$ & 0.076 \\
\hline $\begin{array}{l}\text { Generalized } \\
E P \\
n=27\end{array}$ & $\begin{array}{l}53.1 \\
\pm 19.3\end{array}$ & $\begin{array}{l}57.2 \\
\pm 21.2\end{array}$ & $4.1 \pm 9.7$ & 0.038 & $\begin{array}{l}85(59- \\
206)\end{array}$ & $\begin{array}{l}93(54- \\
225)\end{array}$ & $2.7 \pm 30.3$ & 0.319 & $\begin{array}{l}183.5 \\
\pm 45.1\end{array}$ & $\begin{array}{l}165.5 \\
\pm 32.6\end{array}$ & $\begin{array}{l}-18 \\
\pm 45.4\end{array}$ & $\underline{0.05}$ \\
\hline $\begin{array}{l}\text { Valproate } \\
\quad n=11(41 \\
\%)\end{array}$ & $\begin{array}{l}55.7 \\
\pm 21.2\end{array}$ & $66.6 \pm 24$ & $10.8 \pm 9.9$ & 0.005 & $\begin{array}{l}103.1 \\
\pm 46.8\end{array}$ & $124 \pm 48.8$ & $\begin{array}{l}20.9 \\
\pm 19.1\end{array}$ & 0.005 & $\begin{array}{l}183 \\
\pm 53.8\end{array}$ & $\begin{array}{l}160.1 \\
\pm 35.2\end{array}$ & $\begin{array}{l}-22.9 \\
\pm 37.4\end{array}$ & $\underline{0.07}$ \\
\hline $\begin{array}{r}\text { Lamotrigine } \\
n=3 \text { (11 \%) }\end{array}$ & $\begin{array}{l}60(40- \\
82)\end{array}$ & $\begin{array}{l}62(40- \\
87)\end{array}$ & $2(0-5)$ & 0.180 & $\begin{array}{l}100(62- \\
117)\end{array}$ & $\begin{array}{l}80(68- \\
140)\end{array}$ & $\begin{array}{l}6(-20- \\
23)\end{array}$ & 0.593 & $\begin{array}{l}177 \text { (95- } \\
191)\end{array}$ & $\begin{array}{l}147 \\
(128- \\
199)\end{array}$ & $\begin{array}{l}22(-43- \\
34)\end{array}$ & 1.000 \\
\hline
\end{tabular}




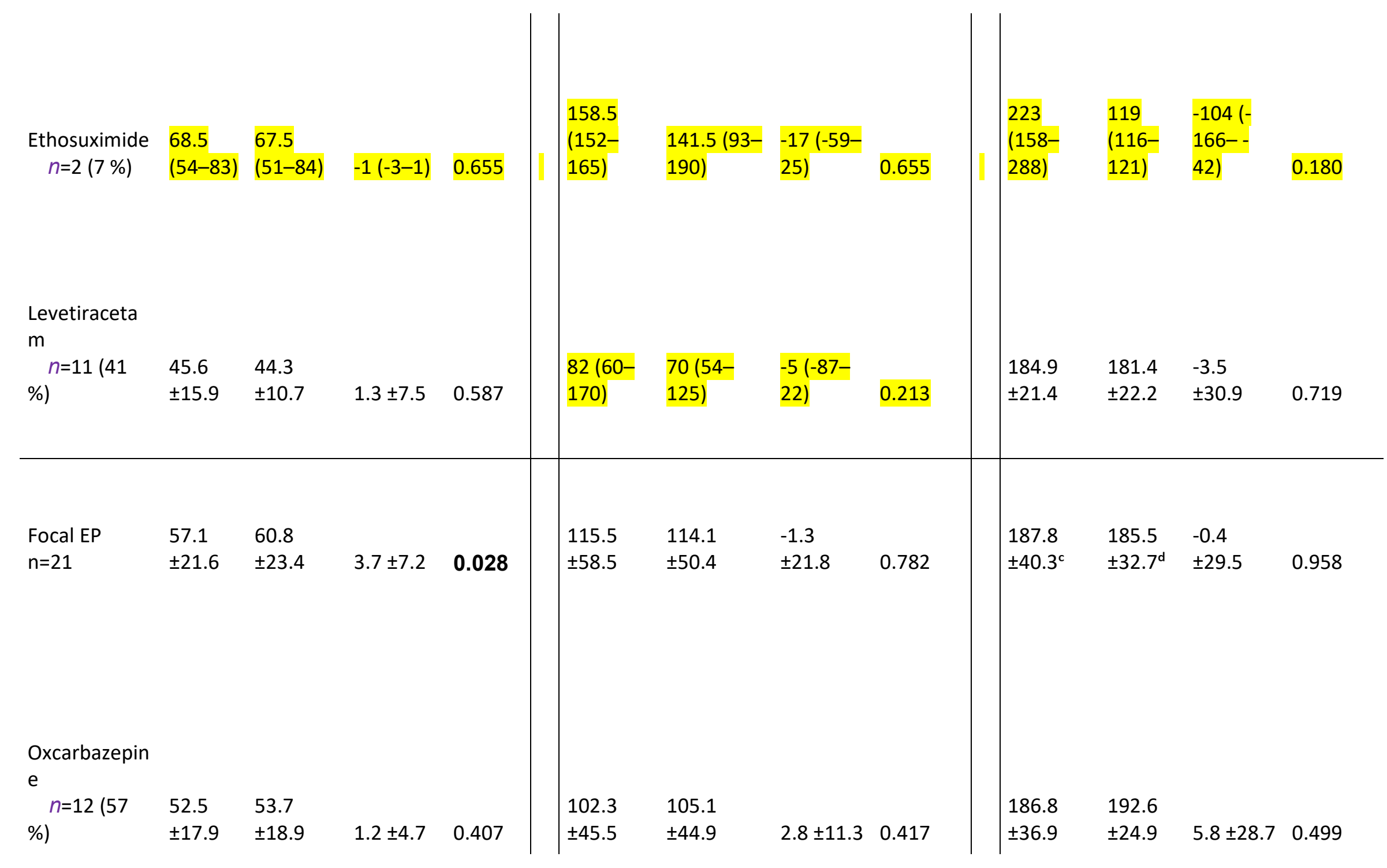




\begin{tabular}{|c|c|c|c|c|c|c|c|c|c|c|c|c|}
\hline $\begin{array}{l}\text { Valproate } \\
n=6(29 \%)\end{array}$ & $\begin{array}{l}67.5 \\
(35-93)\end{array}$ & $\begin{array}{l}80.5 \\
(39-100)\end{array}$ & $\begin{array}{l}6.5(0- \\
28)\end{array}$ & $\underline{0.043}$ & $\begin{array}{l}140 \text { (59- } \\
190)\end{array}$ & $\begin{array}{l}133.5 \text { (59- } \\
190)\end{array}$ & $\begin{array}{l}2.5(-48- \\
40)\end{array}$ & 0.686 & $\begin{array}{l}196 \\
(178- \\
229)\end{array}$ & $\begin{array}{l}167 \\
(159- \\
230)\end{array}$ & $\begin{array}{l}-11(-19- \\
\text { 1) }\end{array}$ & 0.388 \\
\hline $\begin{array}{r}\text { Lamotrigine } \\
n=3(14 \%)\end{array}$ & $\begin{array}{l}37(30- \\
93)\end{array}$ & $\begin{array}{l}42(30- \\
95)\end{array}$ & $2(0-5)$ & 0.180 & $\begin{array}{l}66(57- \\
270)\end{array}$ & $\begin{array}{l}74(68- \\
230)\end{array}$ & $\begin{array}{l}8(-40- \\
11)\end{array}$ & 1.000 & $\begin{array}{l}165(98- \\
254)\end{array}$ & $\begin{array}{l}185 \\
(98- \\
188)\end{array}$ & $\begin{array}{l}0(-67- \\
20)\end{array}$ & 0.593 \\
\hline
\end{tabular}

$a=47 ; b=45 ; c=20 ; d=18$. EP=Epilepsy, RMT=resting motor threshold, 1=before treatment, $2=$ =after treatment, $\Delta=$ difference between measurement 1 and $2, \mathrm{~V} / \mathrm{m}=$ volt $/ \mathrm{meter}, \mathrm{CSP}=$ cortical silent period, $\mathrm{ms}=$ milliseconds. Measurements were displayed as mean \pm standard deviation or median (range). Dependent samples t-test was used to calculate difference between measurement 1 and 2 for parametric variables and Wilcoxon Signed Rank Test for non-parametric variables. 